\title{
Studi korelasi : kualitas tidur dan HbA1C pada pasien lanjut usia di poliklinik penyakit dalam RSUP Sanglah
}

\author{
Narakusuma Wirawan', IGP Suka Aryana ${ }^{2}$, RA Tuty Kuswardhani ${ }^{2}$
}

${ }^{1}$ Program Studi Pendidikan Dokter Spesialis Penyakit Dalam, Fakultas Kedokteran Universitas Udayana/ RSUP Sanglah, Denpasar, Bali, Indonesia

${ }^{2}$ Departemen/KSM Penyakit Dalam, Fakultas Kedokteran Universitas Udayana/RSUP Sanglah, Denpasar, Bali Indonesia

Tanggal diterima : 29 Juli 2017 Tanggal Disetujui : 10 ktober 2017 Tanggal Diterbitkan : 13 Oktober 2017
Latar Belakang: Kualitas tidur yang tidak adekuat dapat berimplikasi negatif pada lansia. Kualitas dan durasi tidur diidentifikasi berkorelasi negatif terhadap kadar HbA1C.

Tujuan: Penelitian ini bertujuan mengevaluasi kualitas dan durasi tidur malam hari tentang korelasinya terhadap kadar gula darah pada lansia menggunakan instrumen skrining yang valid (Pittsburg Sleep Quality Index) dan pengukuran kadar HbA1C setelah dilakukan penyesuaian dengan berbagai variabel perancu.

Metode: Desain cross-sectional dengan pola rekrutmen consecutive random sampling. Total sampel penelitian ini adalah 55 orang, 35 laki-laki (65\%) dan 20 wanita (35\%); dengan rataan umur $63,53 \pm 3,3$. Prosedur pengambilan data meliputi wawancara terstruktur (demografi, dan kuesioner PSQI) dan pencatatan gula darah dan HBA1C pasien melalui data rekam medis. Uji statistik menggunakan Spearman dan regresi linier.

Hasil: Terdapat korelasi negatif antara kualitas tidur terhadap HbA1C (Spearman rho $=-0.345, p<0,005)$. Analisis regresi linier yang melibatkan semua faktor perancu didapatkan hasil depresi memiliki korelasi yang lebih kuat dibandingkan kualitas tidur $(r=-0,400, p<0,005)$.

Simpulan: Kualitas tidur yang buruk dapat menyebabkan terjadinya peningkatan resistensi insulin dan penurunan efektivitas hormon insulin sehingga diperlukan kualitas tidur yang cukup untuk memperoleh kontrol glikemik yang optimal.

Kata kunci: Lansia, Kualitas tidur, PSQI, kadar HBATC

Background: Inadequate night sleep quality has negative implication to the elderly patients. Poor sleep quality and short night sleep duration correlated negatively to glicemic control. However, the correlation study of night sleep quality on $\mathrm{HbA1C}$ levels is still very limited.

Objective: The aim of this study is to evaluate more deeply the relationship of night sleep quality on HbA1C levels in elderly patients.

Method: Total subject of this study is 55 person ( 35 man (65\%) and 20 woman (35\%); mean of age $63,53 \pm 3,3$ ). Sleep quality evaluated using a valid screening instrument (Pittsburgh Sleep Quality Index) and measurement of HbA1C after adjustments were made with confounding variables. Cross-sectional design was selected with consecutive random sampling. Data collection procedure includes structured interview (demographic, questionnaire PSQI, MMSE and GDS) and recording of blood sugar through medical record (HbA1C). Statistical test using spearman and linear regression. Result: From 55 included samples, there is a negative correlation between night sleep quality with the HbA1C ( $r=$ $-0,345, p=0,000)$. Linear regression analyze for all of confounding variable conclude that depression in elderly have strongest correlation than sleep quality $(r=-0,400, p=0,000)$.

Conclusion: Poor quality of sleep may lead to an increase of HbA1C in elderly patients. A good quality of sleep is required to obtain optimal glicemic control.

Keyword: Elderly, night sleep quality, PSQI, HbA1C

\section{PENDAHULUAN}

Berdasarkan studi epidemologi terbaru, perkembangan penyakit degeneratif di Indonesia telah memasuki epidemi diabetes melitus tipe 2. Diabetes militus tipe 2 merupakan model biologis penuaan dengan angka morbiditas dan mortalitas yang tinggi. Menurut Internasional Diabetes Federation (IDF), 75\% kematian pada penderita diabetes melitus tipe 2 disebabkan oleh penyakit komplikasinya. ${ }^{1}$ Sekitar 50\% lansia mengalami intoleransi glukosa dengan 
kadar gula darah puasa normal.,

Studi epidemiologi menunjukkan bahwa prevalensi Diabetes Melitus maupun Gangguan Toleransi Glukosa (GTG) meningkat seiring dengan pertambahan usia, menetap sebelum akhirnya menurun. Dari data WHO didapatkan bahwa setelah mencapai usia 30 tahun, kadar glukosa darah akan naik 1-2 mg\%/tahun pada saat puasa dan akan naik sebesar 5,6-13 mg\%/tahun pada 2 jam setelah makan. ${ }^{1,3}$ Seiring dengan pertambahan usia, lansia mengalami kemunduran fisik dan mental yang menimbulkan banyak konsekuensi. Selain itu, kaum lansia juga mengalami masalah khusus yang memerlukan perhatian antara lain lebih rentan terhadap komplikasi makrovaskular maupun mikrovaskular dari DM dan adanya sindrom geriatri. ${ }^{3}$

Beberapa tahun terakhir, bukti dari studi laboratorium yang dikumpulkan menegaskan bahwa kualitas tidur yang buruk dapat mengganggu regulasi glukosa ke jaringan dan meningkatkan resiko diabetes militus tipe 2. Dua penelitian laboratorium melaporkan terjadi gangguan pada regulasi glukosa pada restriksi tidur yang parsial. Pada studi pertama, pasien yang tidur dengan kualitas tidur yang buruk selama 5 hari ditemukan berasosiasi dengan penurunan toleransi glukosa sebanyak $40 \%$ dan penurunan respon hormon insulin sebesar 30\%. Penemuan ini dikonfirmasikan dengan penelitian yang kedua yang menggunakan metode randomized cross-over design dengan restriksi tidur dibandingkan pemanjangan durasi tidur selama 2 malam (durasi tidur 4 jam vs 10 jam). ${ }^{4}$ Penelitian ini mendapatkan hasil bahwa HBA1C pada pada pasien dengan durasi tidur 4 jam lebih tinggi dengan level insulin yang lebih rendah dibandingkan dengan durasi tidur 10 jam.

Selain bukti penelitian tersebut ditemukan juga suatu penelitian yang dapat dijadikan acuan sebagai penyebab buruknya control glikemik pada lansia dengan kualitas tidur yang kurang. Penelitian itu mengungkapkan bahwa tidur merupakan regulator yang kuat dalam mengatur nafsu makan, penggunaan energi dan kontrol berat badan. Selama tidur, tubuh meningkatkan produksi leptin (supressor nafsu makan) dan menurunkan grehlin (stimulan nafsu makan). Sehingga pasien yang kualitas tidur yang buruk dengan durasi tidur yang pendek akan akan cenderung meningkatkan asupan kalori sehingga akan terjadi peningkatan glukosa darah. ${ }^{5}$ Oleh karena itu, untuk membuktikan teori-teori pendukung diatas diperlukan suatu penelitian pada pasien lansia, dalam hal ini peserta studi diambil dari poliklinik penyakit dalam RSUP Sanglah. Penelitian ini bertujuan mengevaluasi kualitas tidur dan hubunganmya terhadap control glikemik (HbA1C) pada pasien lansia pada poliklinik RSUP Sanglah setelah dilakukan penyesuaian dengan berbagai faktor resiko yang penting

\section{METODE}

\section{Rancangan Penelitian}

Penelitian menggunakan rancangan cross-sectional analitik. Penelitian dilakukan dalam tiga minggu (18 Agustus-7 September 2015) pada poliklinik penyakit dalam RSUP Sanglah.

\section{Sampel}

Penelitian dipilih dengan cara consecutive random sampling. Kriteria inklusi dipakai pasien yang berumur lebih dari 60 tahun yang melakukan rawat jalan pada poliklinik penyakit dalam RSUP Sanglah. Kriteria eksklusi ditetapkan untuk mengeliminasi sampel yakni pasien yang menderita penyakit neoplastik tahap awal sampai lanjut, ketidakmampuan untuk diwawancara karena masalah sosiolinguistik, ketidakmampuan kognitif untuk diikutsertakan dalam penelitian ini, Penderita DM tipe 2 yang sedang dalam terapi dan sedang bekerja pada malam hari (shift malam) selama sebulan terakhir.

\section{Prosedur}

Subyek yang telah sesuai dengan kriteria inklusi dilakukan wawancara terstruktur oleh pewawancara yang terlatih. Wawancara meliputi pertanyaan untuk kriteria ekslusi dan kuisioner MMSE, GDS dan PSQI. Subyek dipakai sebagai sampel apabila skor MMSE diatas 22. Subyek diperiksa HbA1C dan hasilnya dicatat pada kuisioner pasien.

\section{Instrumentasi Skrining dan Pengukuran.}

Kuesioner PSQI adalah alat skrining yang simpel, tidak invasif dan tervalidasi untuk menilai kualitas tidur. Terdiri dari penilaian obyektif yang meliputi durasi tidur, kualitas tidur secara subjektif, efisiensi tidur, Gangguan tidur, penggunaan obat tidur dan aktivitas sehari-hari yang berkaitan dengan tidur. ${ }^{6}$ PSQI sangat mudah digunakan, terstruktur, relatif murah, sangat sensitif, spesifisitas tinggi, dan sangat andal digunakan sebagai pengukur kualitas tidur., ${ }^{6,8}$ Subyek dikelompokkan menjadi dua kelompok sesuai dengan kualitas tidur baik atau buruk. Dalam penelitian ini kualitas tidur yang dimaksud adalah kualitas tidur malam hari. ${ }^{7,8}$

HbA1C didefinisikan sebagai pengukuran rata-rata konsentrasi glukosa darah dalam waktu 1-3 bulan sebelumnya. Hemoglobin terglikasi (HbA1c) merupakan gugus heterogen yang terbentuk dari reaksi kimia antara glukosa dan hemoglobin. Diukur dengan metode HPLC (High Performance Liquid Chromatography) dengan rujukan normal $<7 \%{ }^{4}$

\section{Statistik}

Analisis statistik dilakukan menggunakan SPSS 16.0 (Windows version; SPSS Inc, Chicago [IL], USA). Perbedaan 
rerata HbA1C pada kedua kelompok kualitas tidur diuji dengan independen $t$ test. Korelasi antara kualitas tidur dan HbA1C dinilai menggunakan Spearman test. Perbandingan kuat hubungan antara kualitas tidur dibandingkan dengan faktor perancu terhadap $\mathrm{HbA1C}$ akan dianalisa dengan regresi linier.

Tabel 1. Karakteristik dasar dan demografi berdasarkan kualitas tidur*

\begin{tabular}{|c|c|c|c|}
\hline Variabel & & Total $(n=55)$ & \\
\hline \multirow{2}{*}{ Umur } & & $\begin{array}{c}\text { Kualitas tidur } \\
\text { baik (37) }\end{array}$ & $\begin{array}{c}\text { Kualitas } \\
\text { Tidur buruk } \\
\text { (18) }\end{array}$ \\
\hline & Pekerjaan & & \\
\hline Tidak Bekerja & & $23(72,2 \%)$ & $18(100 \%)$ \\
\hline Petani & & $4(5,8 \%)$ & $0(0,00 \%)$ \\
\hline Pedagang & & $4(5,8 \%)$ & $0(0,00 \%)$ \\
\hline \multirow[t]{2}{*}{ Lain-lain } & & $6(17,2 \%)$ & $0(0,00 \%)$ \\
\hline & Aktivitas & & \\
\hline Ringan & & $25(72,2 \%)$ & $18(100 \%)$ \\
\hline Moderate & & $10(23 \%)$ & $0(0,00 \%)$ \\
\hline \multirow[t]{2}{*}{ Berat } & & $2(5,80 \%)$ & $0(0,00 \%)$ \\
\hline & Tingkat & & \\
\hline Tidak Sekolah & Pendidikan & $2(5,87 \%)$ & $8(40,00 \%)$ \\
\hline SD & & $9(23,12 \%)$ & $5(30,00 \%)$ \\
\hline SMP & & $9(23,12 \%)$ & $3(20,00 \%)$ \\
\hline SMA & & $9(25,22 \%)$ & $1(5,00 \%)$ \\
\hline S1 & & $5(14,23 \%)$ & $1(5,00 \%)$ \\
\hline \multirow[t]{2}{*}{ S2 keatas } & & $3(8,44 \%)$ & $0(0,00 \%)$ \\
\hline & Jenis & & \\
\hline Laki-laki & Kelamin & $23(62,2 \%)$ & $12(67 \%)$ \\
\hline \multirow[t]{3}{*}{ Perempuan } & & $14(37,8 \%)$ & $6(33 \%)$ \\
\hline & Geriatric & & \\
\hline & Depression & & \\
\hline Depresi & Scale & $32(85 \%)$ & $14(80 \%)$ \\
\hline \multirow[t]{2}{*}{ Tidak depresi } & & $5(15 \%)$ & $4(20 \%)$ \\
\hline & Kontrol & & \\
\hline Gula darah & Glikemik & 128,27 & 139,83 \\
\hline $\begin{array}{l}\text { sewaktu } \\
\text { HBA1C }\end{array}$ & & 6,22 & 6,99 \\
\hline
\end{tabular}

*All the statistic result based on confidence interval 95\%

\section{HASIL}

Subyek yang diikutkan dalam penelitian berjumlah 55 orang (35 pria, 20 wanita dengan rataan umur $64,56 \pm 8.7$ tahun). Karakter dasar berdasarkan stratifikasi kelompok kualitas tidur dari sampel dapat dilihat pada Tabel 1. Kebanyakan pasien merupakan tidak bekerja, dengan proporsi pada kualitas tidur baik $(72,2 \%)$ dan kualitas tidur buruk (100\%). Hasil wawancara tingkat aktivitas fisik seharihari selama sebulan terakhir menunjukkan proporsi aktivitas ringan lebih banyak dibanding aktivitas sedang dan berat pada masing-masing kelompok kualitas tidur.

Hasil wawancara seluruh pasien dengan kuisioner PSQI didapatkan bahwa mayoritas pasien lansia memiliki kualitas tidur yang baik, hal tersebut ditunjukkan pada kedua kelompok baik pria dan wanita dengan proporsi masing masing $62,2 \%$ dan $70 \%$. Kelompok kualitas tidur baik berjumlah 37 orang dan kualitas tidur buruk 18 orang dengan total sampel berjumlah 55 orang.

Pemeriksaan HbA1C dan gula darah diproleh hasil rerata gula darah sewaktu $129,31 \mathrm{mg} / \mathrm{dL} \pm 68,43 \mathrm{mg} / \mathrm{dL}$ dan rata-rata gula $\mathrm{HbA1C} 6,23 \mathrm{mg} / \mathrm{dL} \pm 2,5 \mathrm{mg} / \mathrm{dL}$ Kualitas tidur yang buruk memiliki kadar $\mathrm{HbA1C}$ yang lebih tinggi dengan rerata $6,99 \mathrm{mg} / \mathrm{dl}$ dibandingkan kualitas tidur yang baik dengan rerata $6,22 \mathrm{mg} / \mathrm{dl}$. Pada uji perbandingan rerata didapatkan perbedaan rerata 0,77 dengan nilai $p=0,132$. Data tersebut membuktikan adanya selisih kadar HbA1c antara kelompok kualitas tidur yang baik dan kualitas tidur yang buruk namun secara statistik tidak bermakna. Proporsi yang lebih rinci mengenai kadar $\mathrm{HbA1C}$ dan data karakteristik lain berdasarkan kualitas tidur dapat dilihat pada Tabel 1.

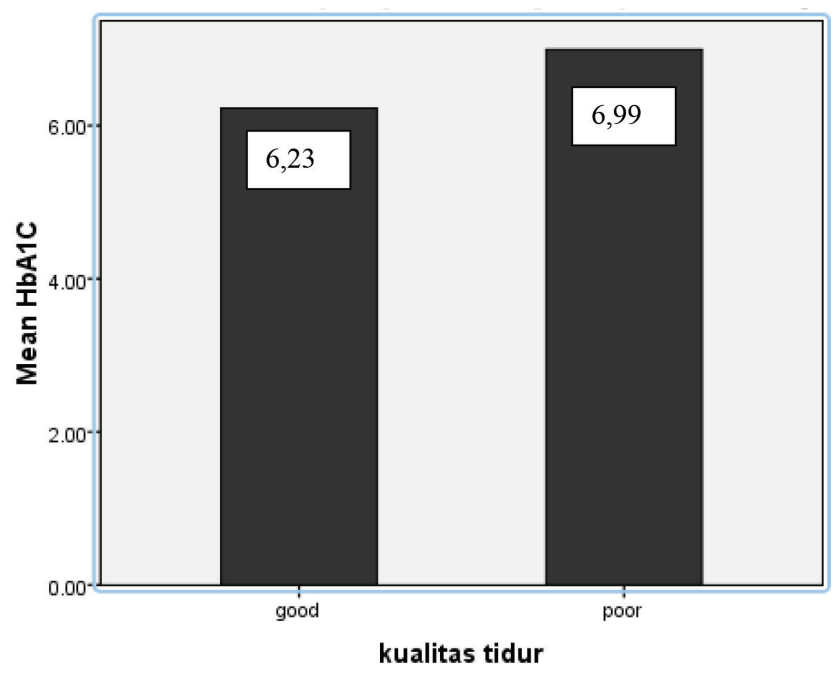

Gambar 1. Perbedaan rerata HbA1c antara kualitas tidur baik dan buruk 
Hasil uji korelasi didapatkan kualitas tidur berkorelasi negatif dengan HbA1C pada level yang signifikan dengan kuat korelasi derajat sedang [Tabel 2]. Faktor perancu yang didefinisikan pada penelitian ini meliputi aktivitas fisik 3 bulan terakhir, usia, jenis kelamin dan depresi. Pada hasil uji regresi linier didapatkan status depresi memiliki korelasi yang lebih kuat dibandingkan dengan kualitas tidur pada level yang signifikan.

Table 2. Spearman Correlation antara kualitas tidur dan kadar HbA1C.

\begin{tabular}{lrr}
\hline Variabel & HbA1C & P value \\
\hline Kualitas tidur & -0.345 & $\mathrm{P}=0,000$ \\
Aktivitas & -0.183 & $\mathrm{P}=0,088$ \\
Usia & -0.170 & $\mathrm{P}=0,025$ \\
Jenis kelamin & -0.196 & $\mathrm{P}=0,033$ \\
Geriatric depression scale & -0.400 & $\mathrm{P}=0,000$ \\
\hline
\end{tabular}

\section{DISKUSI}

Ditemukan fakta yang mengejutkan mengenai hubungan kualitas tidur terhadap kadar HbA1C pada lansia. Didapatkan suatu korelasi negatif yang signifikan dengan besar korelasi sedang antara kualitas tidur terhadap kadar HbA1C. Kelompok kualitas tidur yang buruk memiliki ratarata nilai HbA1C yang lebih tinggi dibandingkan kelompok kualitas tidur baik. Sehingga bisa diperoleh suatu kesimpulan bahwa kualitas tidur yang buruk dapat meningkatkan derajat beratnya DM tipe 2 pada lansia. Hal ini sesuai dengan studi Kirsten dkk tahun 2006 yang mendapatkan kadar HbA1c yang lebih tinggi pada pasien lansia dengan durasi tidur yang kurang dari 6 jam. ${ }^{6}$

Hasil studi ini juga sesuai dengan studi oleh Daniel dkk pada tahun 2005, bahwa pasien yang tidur dengan kualitas tidur yang buruk selama 5 hari ditemukan berasosiasi dengan penurunan toleransi glukosa sebanyak 40\% dan penurunan respon hormon insulin sebesar 30\%. Studi ini diperkuat lagi dengan metode randomized cross-over design dengan restriksi tidur dibandingkan pemanjangan durasi tidur selama 2 malam dan didapatkan $\mathrm{HbA} 1 \mathrm{C}$ pada pada pasien dengan durasi tidur 4 jam lebih tinggi dengan level insulin yang lebih rendah dibandingkan dengan durasi tidur 10 jam. $^{4}$
Hasil analisis regresi linier terhadap variabel perancu menunjukkan bahwa depresi memiliki korelasi yang lebih kuat namun masih dalam kelompok derajat sedang sebagai faktor yang mempengaruhi kadar $\mathrm{HbA} 1 \mathrm{C}$. Hal ini menarik untuk dicermati mengingat variabel tersebut bukan merupakan fokus penelitian, maka diperlukan penelitian lebih lanjut dengan sampel yang lebih besar dan dalam jangka waktu yang lebih lama untuk menentukan efek variabel perancu tersebut.

\section{SIMPULAN}

Hasil studi ini mengindikasikan adanya korelasi negatif dengan besaran sedang antara kualitas tidur terhadap kadar HbA1C pada pasien lansia. Kualitas tidur yang buruk berkontribusi terhadap buruknya kendali gula dalam darah akibat peningkatan resistensi insulin. Pengaruh kualitas tidur bersifat independen terhadap tingkat depresi sehingga hendaknya harus distratifikasi dengan status depresi. Studi lebih lanjut diperlukan untuk menjawab permasalahan yang ditimbulkan variabel pengganggu. Hasil penelitian ini memunculkan argumentasi baru mengenai strategi perbaikan kesehatan penderita lansia terutama pengaturan kualitas tidur yang baik sehingga memperoleh kontrol gula darah yang optimal sebagai upaya preventif maupun monitoring kuratif.

\section{DAFTAR PUSTAKA}

1. Yi L, Zhongjie S. Current views on type 2 diabetes. Journal of Endocrinology. 2010;204:1-11.

2. Juliana C, Vasanti M, Weiping J, dkk. Diabetes in Elderly :Epidemiology, Risk Factors, and Pathophysiology. JAMA. 2014;20:2149-2161.

3. Roepke S, Acoli I. Sleep Disorder in elderly. Indian J Med Res. 2010;131:302-310.

4. Daniel J, Naresh M, Ann B, dkk. Association of Sleep Time With Diabetes Mellitus and Impaired Glucose Tolerance. Arch Intern Med. 2005;165:864-868.

5. Sinclair A, Dunning T, Colagiuri S. Managing Older People with Type 2 Diabetes : GlobalGuidline. IDF. 2013:14-30.

6. Kristen L, Armand M, Bryce A, dkk. Role of Sleep Duration and Quality in the Risk and Severity of Type 2 Diabetes Mellitus in elderly. Arch Intern Med. 2006;166:1768-1774.

7. Budur K, Rodriguez C, Schaefer NF. Advances in Treating Insomnia. Cleaveland Clinic Journal of Medicine. 2014;74:251-266.

8. Summers MO, Crisostomo MI, Stepanski EJ. Recent Developments in the Classification, Evaluation, and Treatment of Insomnia. American College of Chest Physicians. 2013;130:276-286.

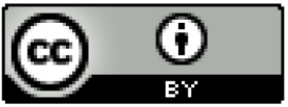

This work is licensed under a Creative Commons Attribution 4.0 International License. 